\title{
Suspension for Injection in Pre-filled Syringe
}

National Cancer Institute

\section{Source}

National Cancer Institute. Suspension for Injection in Pre-filled Syringe. NCI Thesaurus.

Code C149969.

Medicinal product consisting of a suspension for injection presented in a pre-filled syringe. 